\title{
Note: Anodic bonding with cooling of heat-sensitive areas
}

Vesborg, Peter Christian Kjærgaard; Olsen, Jakob Lind; Henriksen, Toke Riishøj; Chorkendorff, Ib; Hansen, Ole

Published in:

Review of Scientific Instruments

Link to article, DOI:

$10.1063 / 1.3277117$

Publication date:

2010

Document Version

Publisher's PDF, also known as Version of record

Link back to DTU Orbit

Citation (APA):

Vesborg, P. C. K., Olsen, J. L., Henriksen, T. R., Chorkendorff, I., \& Hansen, O. (2010). Note: Anodic bonding with cooling of heat-sensitive areas. Review of Scientific Instruments, 81(1), 016111.

https://doi.org/10.1063/1.3277117

\section{General rights}

Copyright and moral rights for the publications made accessible in the public portal are retained by the authors and/or other copyright owners and it is a condition of accessing publications that users recognise and abide by the legal requirements associated with these rights.

- Users may download and print one copy of any publication from the public portal for the purpose of private study or research.

- You may not further distribute the material or use it for any profit-making activity or commercial gain

- You may freely distribute the URL identifying the publication in the public portal

If you believe that this document breaches copyright please contact us providing details, and we will remove access to the work immediately and investigate your claim 


\title{
Note: Anodic bonding with cooling of heat-sensitive areas
}

\author{
Peter C. K. Vesborg, a) Jakob L. Olsen, Toke R. Henriksen, ${ }^{\text {b) }}$ \\ Ib Chorkendorff, and Ole Hansen ${ }^{\text {b) }}$ \\ Department of Physics, CINF, Technical University of Denmark (DTU), Building 312, Fysikvej, \\ DK-2800 Kgs. Lyngby, Denmark
}

(Received 26 August 2009; accepted 3 December 2009; published online 26 January 2010)

\begin{abstract}
Anodic bonding of silicon to glass always involves heating the glass and device to high temperatures so that cations become mobile in the electric field. We present a simple way of bonding thin silicon samples to borosilicate glass by means of heating from the glass side while locally cooling heat-sensitive areas from the silicon side. Despite the high thermal conductivity of silicon, this method allows a strong anodic bond to form just millimeters away from areas essentially at room temperature. (C) 2010 American Institute of Physics. [doi:10.1063/1.3277117]
\end{abstract}

The highly useful phenomenon - that silicon (with a thin oxide layer) may form an impressively strong bond to glass when the two materials are brought into intimate contact under the influence of strong electric fields and high temperature, anodic bonding (also known as "Mallory bonding," named after the company where it was invented and patented $^{1}$ )— has been known and used for many years. ${ }^{2}$

The process is particularly useful for microelectromechanical system (MEMS) pressure sensors and other transducers and in weather sealing of solar cells because the bond hermetically seals the surfaces together. ${ }^{3}$ In our research group we use the process for sealing $\mu$-reactors for catalyst characterization; ${ }^{4}$ however for this application the high temperatures needed for successful anodic bonding may cause catalysts to sinter or otherwise lose activity. An example of this is Au-based catalysts, which are notorious for deactivating since activity is dependant on very small Au particle size. This paper describes a practical way to overcome this issue by locally cooling the chip while the rest of it bonds. This method has proven practical and reliable in our implementation and could be useful for many other MEMS applications.

In brief, anodic bonding works by applying a large $(\sim \mathrm{kV})$ negative bias on the glass with respect to the silicon while at the same time heating the stack such that cations in the glass become somewhat mobile. The electric field set up over the interface causes migration of ions (typically $\mathrm{Na}^{+}$for normal glass types) away from the interface, which sets up an intrinsic electrostatic attraction between the silicon and the glass. No external force is therefore required as the internal forces set up by this field are very strong (pressure in the GPa range). ${ }^{3,5}$ True chemical bonds are formed between the $\mathrm{Si}$ and the glass permanently bonding the two surfaces. A schematic of the process is shown in Fig. 1. The downside of the technique is the inherent necessity of elevated temperatures to give the cations reasonable mobility in the glass. ${ }^{6}$ In some applications a typical bonding procedure for borosilicate-type glass (e.g., Pyrex) to silicon (e.g., $30 \mathrm{~min}$ at $350^{\circ} \mathrm{C}$ ) may well exceed the thermal budget of parts of the

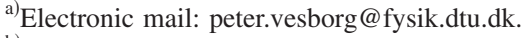

b) Also at Dept. of Micro- and Nanotechnology, Technical University of Denmark, DTU Nanotech Building 345 East, DK-2800 Kgs. Lyngby, Denmark.
}

device. In such cases the traditional remedy is to use glass types that conduct at lower temperatures. A typical strategy might be a lithium doped glass-ceramics, ${ }^{7}$ but generally the process still does not work below perhaps $\left.160^{\circ} \mathrm{C}\right),{ }^{7,8}$ and differences in thermal expansion coefficients might be problematic for these glass types, while conventional borosilicate glass is well matched to Si. Another method is lowtemperature soldering with, e.g., In/Sn eutectic mixtures; ${ }^{9}$ however necessary measures to avoid oxidation of the solder make this method unsuited for general use in open air, and the minimum temperature for this method is also $\sim 160^{\circ} \mathrm{C}$. Devices may also be sealed with adhesives, but (un)cleanliness and leakage makes this unattractive.

Conventional (hot) anodic bonding is shown in Fig. 1, while the locally cooled-bonding method we have developed may be seen in cross section in Fig. 2. There are a few key differences to note. First, since it is the glass (not the silicon) that needs to be warm we apply heat from the glass side. The heater also serves as high tension cathode. Second, the heater only touches the glass where bonding is needed and heat is acceptable. Third, we have introduced a heat sink (cold finger), which also serves as electrical connection to ground, and the heat sink only touches the silicon in the areas where low temperature (and not bonding) is needed. In our setup, the cold finger supporting the silicon and the hole in the heater are both cylindrical, giving the advantage of radial symmetry (no corners with stress concentration) when parts of the system heat and cool.

As a practical method for heating the top electrode, we use two commercial $150 \mathrm{~W}$ incandescent lamps with quartz envelopes (Osram) embedded in holes in the top electrode, which is made of aluminum for its high thermal conductivity. Quartz is insulating well above the relevant temperatures, so the power supply for the filaments does not need galvanic isolation and is indeed grounded in our setup. The heat sink is machined from copper and has internal channels for coolant flow. It is kept at a constant temperature (typically $6-12^{\circ} \mathrm{C}$, but this could well be lower if needed) using a commercial circulating cooling bath. Thermal contact between the silicon and the $\mathrm{Cu}$ pillar may be assured with conventional heat sink compounds or a thin indium foil. For our conditions ( $1 \mathrm{kV}$ potential drop and $475^{\circ} \mathrm{C}$ cathode temperature), bonding is normally complete within $20-25 \mathrm{~min}$. 


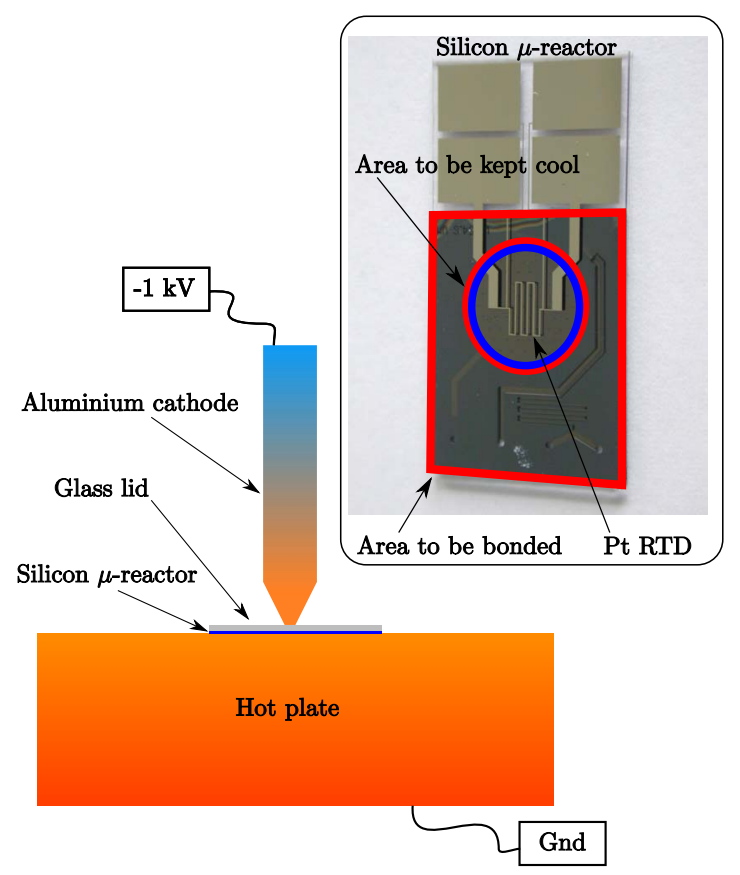

FIG. 1. (Color online) Cross section of a typical hot anodic bonding setup. The glass-silicon assembly is supported on a grounded hotplate and is contacted by a high tension cathode from above. The inset shows a photograph of our $\mu$-reactor and highlights the areas to be bonded as well as the central reactor area, which is to be kept cold during bonding (inner blue circle). In the center of the circle (and reactor), the meander platinum RTD structure on the inside of the glass lid may be seen.

In order to find out what the temperature inside the reactor is during bonding, we have performed a direct measurement inside the reactor using resistive temperature detection (RTD) and also carried out a finite-element-type

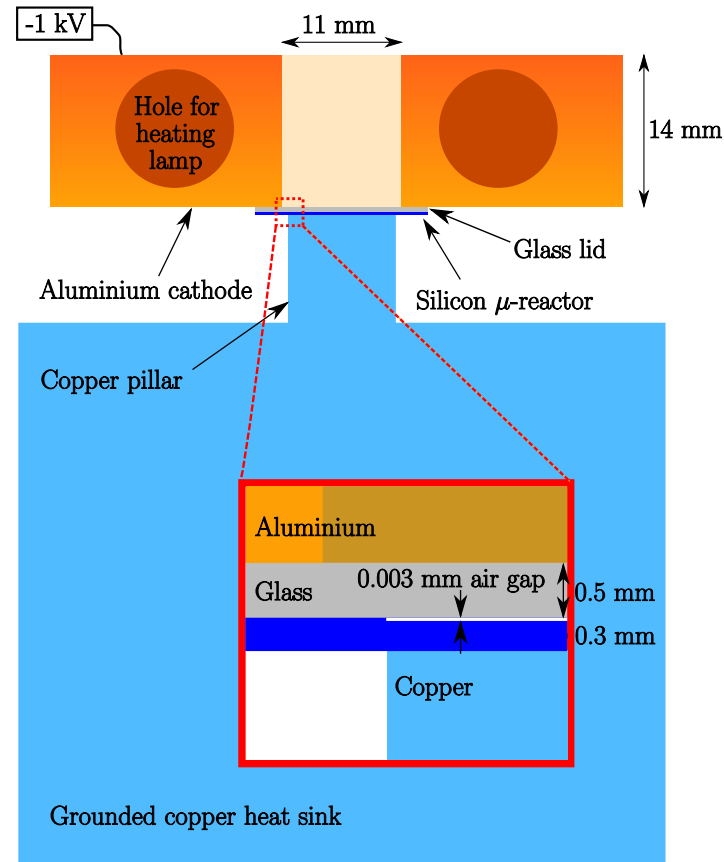

FIG. 2. (Color online) Cross-sectional view showing the locally cooledbonding setup. The grounded $\mathrm{Cu}$ pillar is kept cold and acts as a heat sink during bonding, while the cathode is kept at high temperature so that it simultaneously supplies the high voltage and heats the glass. Over the $\mathrm{Cu}$ cold finger a cylindrical hole is drilled in the cathode, so only a minimum of heat is transferred to the central (reactor) part of the chip.

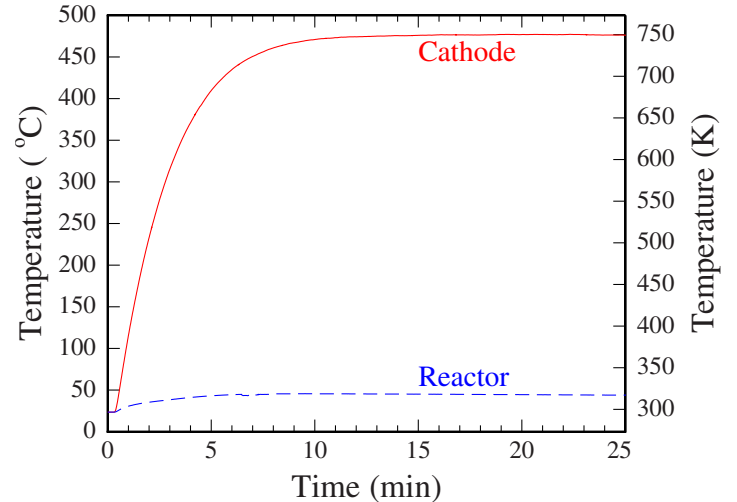

FIG. 3. (Color online) Thermocouple measurement of the aluminum cathode temperature and RTD measurement of the reactor chamber temperature.

calculation using the COMSOL MULTIPHYSICS 3.5 software package. For the four-point RTD measurement, we have used our standard RTD $\mu$-reactor lids, which incorporate a $100 \mathrm{~nm}$ thick platinum four terminal resistor structure and contact pads for making the four connections, as may be seen in Fig. 1 and detailed in Ref. 4. For the purpose of measuring the temperature inside the $\mu$-reactor during bonding, we turned the lid "upside down" so that the Pt RTD was inside the $\mu$-reactor. As a result, the measured RTD temperature corresponds to the temperature inside the reactor. The temperature of the aluminum top cathode was also recorded using a K-type thermocouple. The measurements are plotted in Fig. 3. It is seen that the cathode stabilizes at $\sim 475^{\circ} \mathrm{C}$, while the RTD temperature inside the reactor only reaches $45^{\circ} \mathrm{C}$.

In the finite element analysis (FEA), the real bonding arrangement was approximated with an axially symmetric geometry similar to the actual setup.The steady state temperature distribution was computed. The geometry of the FEA and the predicted temperature distribution are shown in Fig. 4. In the bonding setup a thermal contact resistance is expected between the aluminum and Pyrex. This was represented in the simulations by a narrow subdomain along the aluminum-Pyrex interface, giving rise to a thermal contact resistance of $5 \times 10^{-5} \mathrm{~m}^{2} \mathrm{~K} \mathrm{~W}^{-1}$. In the FEA a constant tem-

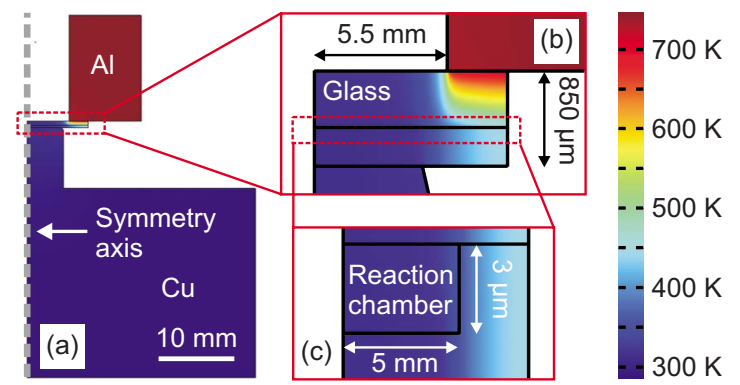

FIG. 4. (Color online) Geometry and color plot of the calculated steady state temperature distribution from the FEA. The geometry is an axially symmetric approximation of the real cooled-bonding setup. (a) The entire geometry with equal scale on both coordinate axes. The vertical dashed gray line signifies the symmetry axis. The silicon and the glass chip are stacked between the aluminum cathode and the copper heat sink. (b) Magnification of the silicon and glass chip. A high temperature gradient is observed in the part of the Pyrex lid outside the reaction chamber. (c) Magnification of the reaction chamber. The temperature in the chamber is seen to be close to room temperature as a result of the cooled-bonding fixture. Note that in (b) and (c) the scaling of the $x$-axis and the $y$-axis is different. 


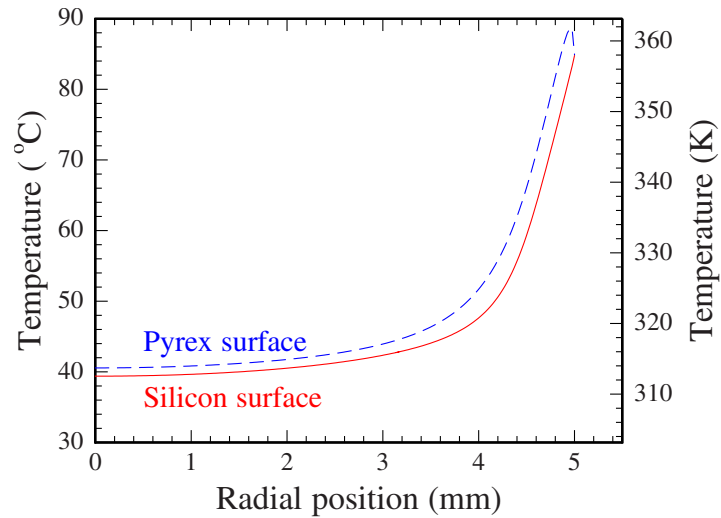

FIG. 5. (Color online) Steady state temperature distribution in the reaction chamber as computed in the FEA. The temperature in the chamber as a function of radial position is shown. The radial position is the distance from the center axis of the chamber (the symmetry axis). In the plot, the temperature in the top of the chamber adjacent to the Pyrex is shown (blue dashed curve) as well as the temperature in the bottom of the chamber adjacent to the silicon (red full curve).

perature of $475^{\circ} \mathrm{C}$ was applied to the right boundary of the aluminum block. The bottom of the copper block was set to a constant temperature of $12.5^{\circ} \mathrm{C}$, and the reaction chamber was treated as containing atmospheric air. The FEA gives detailed information about the thermal gradients from which, e.g., heat fluxes and thermal expansion can be extracted. Figure 5 shows the temperature in the reaction chamber as a function of radial position according to the FEA. It is seen that the predicted temperature is below $90^{\circ} \mathrm{C}$ everywhere and below $50^{\circ} \mathrm{C}$ within the central $8 \mathrm{~mm}$ diameter circle in the chamber. In the center of the chamber the FEA predicts a temperature of around $40^{\circ} \mathrm{C}$, which is in good agreement with the experimental result $45^{\circ} \mathrm{C}$ (Fig. 3).

For evaluation of the scalability of the method, it is useful to consider a design where the radial distance between heater and cold finger edges is sufficient to ensure that a region (outside the cooled air-gap region) of purely radial heat flow exists. In the present system such a region would be the cylindrical cross section with a radius of $\sim 5.2 \mathrm{~mm}$ (to good approximation). In that region the ratio of heat flows in glass $P_{\mathrm{G}, \mathrm{r}}$ and silicon $P_{\mathrm{Si}, \mathrm{r}}$ is $P_{\mathrm{G}, \mathrm{r}} / P_{\mathrm{Si}, \mathrm{r}}=\left(\varkappa_{\mathrm{G}} h_{\mathrm{G}}\right) /\left(\varkappa_{\mathrm{Si}} h_{\mathrm{Si}}\right)$, while the total heat flow is $P_{\mathrm{tot}}=P_{\mathrm{G}, \mathrm{r}}+P_{\mathrm{Si}, \mathrm{r}}$; here and below $\varkappa_{\mathrm{i}}$ and $h_{\mathrm{i}}$ are the thermal conductivities and material thicknesses, respectively. Then, by continuity, in the reactor region the heat flow in the glass will be directed through the air film in the reactor and cause a (mean) temperature difference $\Delta T=P_{\mathrm{G}, \mathrm{r}} h_{\mathrm{air}} /\left(\varkappa_{\mathrm{air}} \pi a^{2}\right)$ between top and bottom of the reactor; $a$ is the radius of the reactor chamber. It follows that $\Delta T$ will increase approximately linearly with reactor height; in the present design $\Delta T \simeq 4 \mathrm{~K}$ at $h_{\text {air }}=3 \mu \mathrm{m}$, and if arbitrarily the upper acceptable limit is $\Delta T_{\max }=60 \mathrm{~K}$, then the upper limit on the reactor chamber height is $h_{\text {air }} \leq 45 \mu \mathrm{m}$, with all other parameters unchanged. The limit on reactor chamber height may be lifted if forced convection cooling is applied to the glass lid surface through the center bore of the heater.

An increase in the thickness of the glass wafer is also seen to cause an increase in $\Delta T$, but at the same time the heater temperature must be increased since $P_{\mathrm{Si}, \mathrm{r}}$ must be maintained to keep the temperature $T_{\mathrm{B}}$ at the bonding interface fixed.

In the heater and cold finger regions, the heat flow is three-dimensional. The transition to a radial heat flow in the heater region takes place on a length scale that is approximately $h_{\mathrm{G}}+h_{\mathrm{Si}}$, while at the cold finger the transition takes place on a length scale of approximately $h_{\mathrm{Si}}$ since here, the main heat flow is in silicon. It follows that the radial distance between heater and cold finger edges must fulfill $\Delta r_{\mathrm{hc}} \geqslant h_{\mathrm{G}}+2 h_{\mathrm{Si}}$. Moreover, in the region directly above the cold finger, the length scale of the temperature variation is $h_{\mathrm{Si}}$, and thus the cold finger radius must fulfill $r_{\mathrm{Cu}}>h_{\mathrm{Si}}$, say, $2 h_{\mathrm{Si}}$. A minimum applicable chip size could then be estimated from $2 r_{\min } \sim 2\left(2 h_{\mathrm{Si}}+h_{\mathrm{G}}+2 h_{\mathrm{Si}}+w_{\mathrm{H}}\right)$, where $w_{\mathrm{H}}$ is the width of the glass-heater contact; this probably has to fulfill $w_{\mathrm{H}}>h_{\mathrm{G}}+h_{\mathrm{Si}}$, making $2 r_{\mathrm{min}} \sim 2\left(5 h_{\mathrm{Si}}+2 h_{\mathrm{G}}\right)=5.5 \mathrm{~mm}$ with a cold finger radius $r_{\mathrm{Cu}}=0.7 \mathrm{~mm}$. This design was verified by FEA.

With the current design, the temperature $T_{\mathrm{Rc}}$ in the center of the reactor (on the silicon side) is almost entirely controlled by the $\mathrm{Cu}$ cold finger $T_{\mathrm{Rc}} \simeq T_{L}+R_{\mathrm{Cu}} P_{\text {tot }}$, where $T_{L}$ is the cold finger temperature (we have used $T_{L}=12^{\circ} \mathrm{C}$ ) and $R_{\mathrm{Cu}}=L_{\mathrm{Cu}} /\left(\varkappa_{\mathrm{Cu}} \pi r_{\mathrm{Cu}}^{2}\right)+1 /\left(4 \varkappa_{\mathrm{Cu}} r_{\mathrm{Cu}}\right)$ is the thermal resistance of the cold finger of length $L_{\mathrm{Cu}}$ including thermal spreading resistance to the $\mathrm{Cu}$ bulk. It follows that the reactor temperature is linearly dependent on the cold finger temperature, linearly dependent on the total heat flow, and strongly dependent on the cold finger geometry. This also emphasizes the importance of ensuring good thermal contact between silicon and the cold finger; thus we use thermogrease at that junction.

By heating from the glass side of the glass-silicon stack and providing efficient local cooling, we have shown that silicon may be anodically bonded to glass successfully while keeping small $(<1 \mathrm{~cm})$ areas at ambient temperatures. This is highly useful for any MEMS or lab-on-a-chip devices, which contain heat-sensitive components such as polymeric structures or coatings, antibodies, or other biomolecules or sensitive metallic structures. The method may be scaled down to bond individual chips as small as $\sim 5.5 \mathrm{~mm}$ in diameter while keeping $1.4 \mathrm{~mm}$ diameter regions cold. Even smaller dimensions are possible with thinner silicon and Pyrex. Cavities up to $\sim 45 \mu \mathrm{m}$ deep may be used in the existing setup, while still keeping the reactor temperature below $100^{\circ} \mathrm{C}$. Finally, it should be possible to locally cool multiple areas/chips simultaneously when bonding whole wafers. dation.

CINF is funded by the Danish National Research Foun-

${ }^{1}$ P. R. Mallory, U.S. Patent No. 3397278 (1969).

${ }^{2}$ G. Wallis and D. Pomerantz, J. Appl. Phys. 40, 3946 (1969).

${ }^{3}$ K. M. Knowles and A. T. J. van Helvoort, Int. Mater. Rev. 51, 273 (2006).

${ }^{4}$ T. R. Henriksen, J. L. Olsen, P. C. K. Vesborg, I. Chorkendorff, and O. Hansen, Rev. Sci. Instrum. 80, 124101 (2009).

${ }^{5}$ T. R. Anthony, J. Appl. Phys. 54, 2419 (1983).

${ }^{6}$ K. B. Albaugh, J. Electrochem. Soc. 138, 3089 (1991).

${ }^{7}$ S. Shoji, H. Kikuchi, and H. Torigoe, Sens. Actuators, A 64, 95 (1998).

${ }^{8}$ Y. Huang, Z. Cui, G. Xiping, L. Changjiu, and G. Zhenan, J. Non-Cryst. Solids 354, 1407 (2008).

${ }^{9}$ C. Lee, W. Huang, and J. Shie, Sens. Actuators, A 85, 330 (2000). 